\title{
FROM INVENTION DISCLOSURES TO INNOVATION - CHALLENGES IN TRANSFORMING PRACTICE
}

\author{
Kirjavainen, Senni; Björklund, Tua A.
}

Aalto University

\begin{abstract}
Adopting design thinking and innovation-oriented approaches in organizations is crucial but not always simple. New practices of collaboration, user-orientedness and exploration require a compatible culture to be successfully integrated into product development. This paper presents a case study based on 12 interviews of employees and managers in a large Finland-based technology company, introducing new ways of working to product development. Silos, focusing on inventions, and a lack of resources for exploration were highlighted as key challenges in transitioning from incremental development to innovations. Perhaps counterintuitively, introducing new ways of working requiring a collaborative culture - the most widely recognized shortcoming in the current practice in the case - were best received, and support and feedback could be found for pilot projects in these arenas. When the gap between the practice and culture was smaller, change efforts could perhaps be more challenging, as there was less of a consensus on a need to change. The results suggest than developers need not automatically shy away from piloting new ways of working even when existing cultures are not compatible.
\end{abstract}

Keywords: Case study, Collaboration, Cultural transformation, Innovation, Organizational processes

\section{Contact:}

Kirjavainen, Senni

Aalto University

Design Factory

Finland

senni.kirjavainen@aalto.fi 


\section{INTRODUCTION}

Innovativeness has become crucial for company performance in the current "innovation economy" (Sawyer, 2006, p.41). Developing new products, services and ways of operating offer a competitive edge (Porter and Ketels, 2003), but in fast-paced environments, innovation needs to be a continuous effort. In addition to generating new ideas, these need to be effectively operationalized and implemented in organizations (Amabile et al., 1996; Anderson et al., 2014). However, leading such uncertain and ambiguous efforts differs from many traditional management approaches, requiring a balancing act with changing requirements, room for creativity yet efficiency (Amabile et al., 2004; Kim and Wilemon, 2002; Lewis et al., 2002; McDonough III and Barckzak, 1991; Valle and Avella, 2003).

Design approaches and design thinking with their customer-centricity and emphasis on experimentation have received increasing attention amongst both scholars and practitioners as an effective way of organizing innovation (Buchanan, 1992; Brown, 2009; Martin, 2009; Perks et al., 2005; Ravasi and Stigliani, 2012). What starts as a change in product design can end up as a change in strategy (Ravasi and Lojacono, 2005). However, empirical research on how design thinking practices are adopted in established organizations remains limited (Carlgren et al., 2016, Carr et al., 2010; Drews, 2009; Micheli et al., 2019; Seidel and Fixson, 2013). The few extant studies indicate that those new to design thinking may find it hard to engage in multiple experiments and iteration (Rekonen and Hassi 2018, Adams et al., 2003). New approaches need to be legitimized in the organization (Rauth et al., 2015; Mutanen, 2008), and shifting status can generate tensions and resistance (Beckman and Barry, 2007).

In a recent review of empirical research - mainly case studies - Elsbach and Stigliani (2018) found that adopting design and design thinking tools in organizations required a compatible culture, valuing collaboration and experimentation. Silos and a strong focus on productivity and performance can hinder the adoption of new ways of working (Elsbach and Stigliani, 2018). Emphasizing productivity could work against introducing time-consuming co-creation and needfinding tools even if they would save time in the long run (Rauth et al., 2015; Coakley et al., 2014). On the other hand, many of the reviewed studies also suggested there was a bidirectional relationship between methods and organizational culture, where new tools could help to introduce and reinforce new values in the community (Elsbach and Stigliani, 2018). For example, needfinding tools can help transition into a more user-centric culture by exposing employees to customer perspectives and experiences in a salient manner (Elsbach and Stigliani, 2018; Body, 2008; Vetterli et al., 2016). Artifacts and spaces can also communicate new emphases on for example experimentation and collaboration by making them visible in organizations (Elsbach and Stigliani, 2018; Rauth et al., 2015; Stigliani \& Ravasi, 2012).

Despite the strong interconnections seen between new methods and culture, Elsbach and Stigliani (2018) note that these connections have been implicit in most empirical studies (even anecdotal at times, we might add), and call for further research focusing explicitly on the influence of culture on needfinding, idea generation and idea testing methods, and vice versa. Creative processes, methods and skills can be taught (Liu \& Schonwetter, 2004) but they should also be effectively put into operation in businesses. The current study takes up this call, investigating a large technology-based company in the midst of attempting to adopt new co-creative and experimentative ways of working in development. Based on 12 in-depth interviews with 11 employees and managers in different roles in a large technology company, we identify key cultural challenges and perceived leverages when introducing new practices to widen innovation activities. Our focus is not on specific methods and tools used in the case-company, instead we investigate the introduction of design thinking practices on a more process-oriented level in an engineering-driven cultural context to investigate what kinds of needs, practices and hindrances can product development professionals perceive and recognize in an industrial organization pushing for integrating design thinking practices into its development processes.

\section{METHODOLOGY}

We adopted a single case study approach, building on a qualitative analysis of interviews. The selected company was a listed, internationally operating, industrial technology company in Finland. Development work is one of the core functions at the case company, and several initiatives were ongoing to improve the established stage-gate model used for development at the studied company. In 
addition, separate development initiatives around a number of identified issues were ongoing, including piloting co-creation workshops with customers and developing products using design sprints. With the recognized need for changing development practices and a high intensity of ongoing action, the company presented a fertile case for us to examine the transition process from the case company's predominantly traditional, engineering-led ways of developing to incorporating design thinking and its user-centric and cross functional ways of working into the company.

Eleven employees and managers from different levels involved in driving design efforts and working in development and innovation related functions were interviewed on current culture, practices and initiatives. Altogether 12 semi-structured interviews were conducted and included in the analysis, as one of the interviewees was interviewed twice. The majority of the interviewees were men in their thirties to fifties. All of the interviewees held at least a master's degree, mostly from engineering fields, and their experience in the company ranged from six months to more than a decade. The interviews were built around a critical incident approach (Cope \& Watts, 2000; Flanagan, 1954), which made it possible to explore participant-selected meaningful events in the interviewee's experience of engaging in development and innovative work. Participants were asked to describe examples where they had been particularly pleased and displeased with development efforts, as well as describe the company's development-related practices, culture and needs. The interviews lasted for approximately an hour each, and were audio-recorded and transcribed verbatim. Some of the presented quotes have been translated to English.

The transcribed data was coded into segments describing development efforts and development-related practices, culture and needs. These 644 segments were categorized into mutually exclusive categories based on thematic similarity (Braun \& Clarke, 2006). This categorization resulted in seven categories consisting of 18 subcategories.

\section{RESULTS}

\subsection{Case context}

The studied large, technology-based company as a whole was characterized as an engineering-driven company, with a strong R\&D organization good at solving structured problems. The organization was described to consist of strong professionals and experts who tend to have long careers in the company. Many of the product solutions that were developed were described as customized solutions to a particular customer. On the other hand, exploring new possibilities for business and products was not seen as a strength of the company. New opportunities seemed to rise primarily as technical inventions improving existing products, rather than systematic efforts for wider ranges of innovation. Ideas were often discussed synonymous to inventions. One of the interviewees described the experienced emphasis on technological inventions in the company and how design could help expand this with the following words:

"This is an inventor company, so what does it take for it to be an innovation. [...] How [inventions] become innovations, commercial success stories always so there we have a lot to improve, so that we don't protect just anything. This should be brought more into our values. And design thinking is good for that, because then you are designing to meet a need and not based on your gut feeling."

The company had established a stage-gate model for development work. While it was seen as beneficial to have a process for developing products, this was not always adhered to, and some felt that it did not serve the front-end phases very well. The current ways of working were described as siloed and somewhat protective, hindering collaboration and co-creation. The silos were numerous and they were formed on the basis of e.g. competence, age, unit or department. On the other hand, many felt trusted within the silos they were in, with developers and teams getting to work independently towards their goals without being interrupted.

There was also a number of ongoing initiatives with an aim to improve and diversify development efforts carried out in the company. The interviewees were aligned in their descriptions of perceived development needs in the company, and initiatives had been undertaken to start addressing those needs. For example, there had been efforts to create practices for design canvases and design sprints to complement the existing stage-gate model and to increase agile developing internally. These practices had already been piloted inside the company. There were some positive experiences from projects that had been carried out with customer-centric or user-centric front-end phases. To increase this 
collaboration with customers, there had been pilots of co-creation workshops where problems were framed and solved together with the customer in fast-paced workshop of a few days.

\subsection{Described development needs and efforts}

Table 1. Categories and subcategories of development efforts and development-related practices, culture and needs

\begin{tabular}{|c|c|c|}
\hline Category & Subcategory & No. \\
\hline \multirow[t]{6}{*}{ Collaboration (263) } & Silos & 67 \\
\hline & No silos or working across them & 11 \\
\hline & Lack of collaboration & 64 \\
\hline & Lack of and need for practices for collaboration & 52 \\
\hline & Positive experiences of collaboration & 35 \\
\hline & Existing practices for collaboration & 34 \\
\hline \multirow{3}{*}{$\begin{array}{l}\text { Focus on inventions rather } \\
\text { than innovation (108) }\end{array}$} & Emphasis on inventions, existing business and sales & 80 \\
\hline & A need for innovation and new business & 25 \\
\hline & Innovation driving development & 3 \\
\hline \multirow{4}{*}{$\begin{array}{l}\text { Exploration in early- } \\
\text { phases of product } \\
\text { development (104) }\end{array}$} & Need for exploration & 48 \\
\hline & Positive experiences of exploration & 20 \\
\hline & $\begin{array}{l}\text { No exploration taking place or people not being willing to } \\
\text { explore }\end{array}$ & 19 \\
\hline & Lack of resources and support for exploration & 17 \\
\hline \multirow[t]{3}{*}{ Customer insights (81) } & Need for user and customer-oriented approaches & 36 \\
\hline & Lack of customer-oriented approaches & 25 \\
\hline & $\begin{array}{l}\text { Positive experiences of going to customers and efforts to } \\
\text { develop user and customer-oriented practices }\end{array}$ & 20 \\
\hline \multirow{2}{*}{$\begin{array}{l}\text { Culture of questioning } \\
\text { (41) }\end{array}$} & Lack of questioning ideas, projects or opinions & 36 \\
\hline & Too early critique & 5 \\
\hline Slowness and rigidity (17) & $\begin{array}{l}\text { Slowness of change, slowness of the industry, rigid supporting } \\
\text { functions for development, lack of supporting functions for } \\
\text { development }\end{array}$ & 17 \\
\hline Other (30) & $\begin{array}{l}\text { Generic statements of having unspecified challenges or } \\
\text { strengths, and individual statements of e.g. strategy in relation } \\
\text { to development, making cultural change and wishing for a } \\
\text { reward system }\end{array}$ & 30 \\
\hline Total & & 644 \\
\hline
\end{tabular}


The descriptions of culture, development efforts and development-related practices, hindrances of development and needs regarding development work were categorized into seven categories comprising of 18 subcategories. The categories are as follows: collaboration $(n=263)$, focus on inventions rather than innovation (108), exploration in early-phases of product development (104), customer insights (81), culture of questioning (41), slowness and rigidity (17), and individual segments outside of these categories (30) (Table 1).

\subsubsection{Collaboration}

Collaboration and its importance both inside the company and with its stakeholders was a recurring theme in all of the interviews, with $41 \%(n=263)$ of development related segments describing collaboration. Instances related to internal collaboration were found in all interviews, and collaboration with customers was brought up in ten interviews. The stakeholders that were mentioned in relation to collaboration included universities and potential partner companies in developing new products, consultancies to draw knowledge from, and former employees.

Reflections on the company culture frequently referenced or described silos $(n=67)$ in the engineeringled company. There was some collaboration across different silos or parts of organization that were not siloed $(\mathrm{n}=11)$, but not as much as the interviewees wished for. The dividing factors were described to be plentiful; teams, competences, business areas and sometimes even age or tenure. The siloed company culture was seen as blocking information from being transferred from business line to another, from service units to developers and from sites to developers. This could even be reflected to the customers, as for example when maintenance work took place at a customer's site, employees might be oblivious to problems outside of their own product line. What this meant to development work was that the right problems were not necessarily solved, and project specifications might be misunderstood. A lack of collaboration $(n=64)$ was often described as a hindrance to development inside the company.

Increasing collaboration inside the company and with stakeholders was described as essential in order to better understand the products that are being developed and to create potential value, new business and innovations across business units and product lines. The interviewees were unified in their desire to improve collaboration and dismantle silos. When asking one interviewee what they would change in the company ways of working, the answer was as follows:

"[The first thing I'd change at the company is having] less silos. I would dismantle those barriers between product lines."

One reason for too little collaboration was seen in the lack of practices to support it $(n=52)$. This was the case within the company, but especially with customers. The case-company was portrayed as having established some strong relationships with customers, and some on-site development in collaboration with customers did take place. However, the interviewees found it difficult to find suitable, interested customers for collaboration, and described difficulties in establishing new relationships for collaboration in the early stages of product development. Clearing one's schedule to find time for collaboration was also an issue as the everyday work was prioritized. For example, one interviewee described difficulties in testing and further developing an idea for improving customers' processes:

"We discovered that we can't implement this process idea of ours anywhere, because we have no partner, who could implement this for us. So, it doesn't help if you have a good process if you don't have the equipment of the correct scale."

However, there were some mentions of existing practices for collaboration $(n=34)$ stretching from e.g. digital platforms and customer seminars, to nurturing established relations with customers and ways of forming development teams inside the organization. The reported experiences of collaboration and inter-silo collaboration inside the company were almost without exception described as positive $(\mathrm{n}=35)$. Encouragement for increased collaboration was called for e.g. in these words:

"One of them just told how this technology has to do with [certain technology], and that should be done together with them, but well, it has never been done. - - [They] just started to pour it out, that here we don't do this across these company, like, across these product lines. And that should be somehow encouraged. The know-how is technically good, but it should be cross-bred across and between processes." 


\subsubsection{Focus on inventions rather that innovation in a broader sense}

A strong emphasis on making inventions and improving existing products and business at the cost of creating new innovations was a recurring theme in the interviews $(n=80)$. Ideas were often discussed as a synonym for inventions. This meant considering only ideas with a patentable technical component in them rather than seeing the value of producing a mass of ideas in a range of non-technical aspects as well. Inventions were often the starting point of a project, and in the best cases, they resulted in successful products. At the same time, the focus on inventions and invention disclosures seemed to strengthen the silos and hinder collaboration, as it could lead to a protective attitude towards one's own ideas with potential for invention, as described by an interviewee.

"We've had this problem that out IPR policy and a lot of things support the kind of lone inventor, I mean the compensation levels and these things. And they shut people out because of that, because you get more money for yourself. And that's really problematic."

However, despite these downsides of the invention-oriented culture, the interviewees appreciated the inventions that the "Gyro Gearloose" kind of people in the organization made.

The lack of a wider orientation for innovation was also seen as a result of having the engineering-led culture and having a strong emphasis on existing business and sales. Some interviewees also described a potential for making a better use of the patent portfolio and existing ideas in the early phases of product development in order to avoid duplicating work that has already been done and to build more on others' ideas. There were only a few mentions of situations where innovation was the driving force for development and the interviewees were satisfied with the status quo within their unit $(n=3)$.

The inventions made were often improvements to existing products, even though there was a clear need for innovation and new business $(n=25)$. This incremental development came up mostly in connection with other development-related practices and needs. It was seen as a result of working in silos, coupled with the lack of exploration, testing new ideas and trial and error in the front-end phase. Ideas and potential for innovation were often times also described getting lost in the process of documenting and reporting, while realized development efforts remained sales and delivery-led therefore contributing to bettering existing solutions. The focus of development was described as being too heavily on customized solutions, and some of the interviewees called for developing a stronger product portfolio instead.

"It is a big part of innovativeness that you get to validate things with a customer, but at the same time, it constitutes a lot of concrete work, that is tied, that you have to make this and this report and all other things on top of research. Report and travel and use time on things that don't support for example having come up with something inventive, so under that workload you don't identify it and develop into a product or a patent or whatever. - - So now the aim would be to separate $R \& D$ a bit from the suction of daily work and suction of working with clients"

\subsubsection{Exploration in early phases of product development}

Exploration in the front-end and early stages of product development was seen as important, but also described as something that happens too little and the interviewees described a need for exploration $(\mathrm{n}=48)$. Ideas and concepts were easily taken to a very detailed level while developing multiple options and diverging was often skipped. The interviewees described not having a culture of ideating and exploring, a lack of quick-and-dirty testing and as well as too little vision creation for the future. One of the interviewees described the need for exploration through wishing for more unallocated time: "I'm in favor of freeing time, and giving the opportunity to do a little bit of, like, also reflective work and testing. Testing ideas. Because if something comes up there, it can be taken to this [stage-gate process] then. Let's not make it too difficult in the beginning."

The interviewees described both positive experiences of exploration $(n=20)$ and situations where no exploration took place or people had no will to explore $(n=19)$. Some efforts had already been made to add more exploration into the development process, for example an unallocated experimentation budget had been recently introduced:

"If one of those [ideas] could start with some customer, then actually yes, but we don't know where it leads in the end and this kind of action has been developing, that we accept, that we might have some sum of money to try out good ideas."

Despite the changes towards more experimentation taking place the interviewees still perceived a need for more agility, concepting, visioning, and trying out ideas. Insufficient resources and support $(n=17)$ for such exploration was also brought up. The interviewees described too little money, time, and 
people allocated for exploring opportunities as well as the supporting functions being directed more towards delivery. Despite the lack of space to explore, ideate, and reflect, some interviewees also wished for a structured system for the organization to implement in the early phases of product development as they felt it would support the development work in the early phases.

\subsubsection{Customer insights}

The interviewees recognized both a need for more user and customer-oriented approaches $(n=36)$ as well as current lack of these approaches $(n=25)$. Thus far there had been more experienced sales and deliveries related collaboration, while a need for adopting a stronger user and customer-oriented approach was expressed. Observing the users and going to the sites where the products are used to figure out the actual problem that should be concentrated on happened too rarely. There was also a call for more ideation and development collaboration with the users and customers. Often the lack of these approaches was linked to the lack of practices for collaboration (see Section 3.2.1). This is how one of the interviewees described the mindset some developers in the company manifest:

"We have very strong product lines and there we have people who know their own silo thoroughly. That maybe creates a foundation here at the office for too much of this designing with a gut feeling, because we think we know what is needed and what's the status of the customer. And we have very little of our own manufacturing, so our product developers don't discuss with the makers enough, either."

The interviewees also described positive experiences of going to customers and efforts to develop user and customer-oriented practices $(n=20)$. Instances where the interviewees had had the opportunity to approach the development from a user's point-of-view and make site visits increased understanding and resulted in good ideas and sometimes in innovative new products solving problems the developers had observed in the field.

\subsubsection{Culture of questioning}

One need or a characteristic that came up in the interviews was a lack of questioning $(n=36)$ or challenging ongoing work, ideas, or opinions. Oftentimes, ideas or inventions were developed for a very long period of time, tying up a lot of resources, before they were critically examined. There were cases where the entire development process had been completed before the project was put to an end. The interviewees called for more ability to kill ideas and projects in the early phases of development:

"We should have the courage to say, that no, this is stuck at this gate until this and that have been done. And sort of, that things really wouldn't proceed [...] I think now way too many product development projects go on to the very end. When we should be doing quick and dirty checks, and throw stuff away with the quick and dirty."

On the other hand, it was brought up that sometimes ideas are perhaps unnecessarily shot down by stating that "this has already been tested". This kind of too early critique $(n=5)$ was partly because of the long careers and "gurus", who had extensive experience and knowledge. The culture of "gurus" made it difficult to both challenge ongoing ideas and projects, particularly when development has been taken rather far already, as well as start testing ideas that more experienced colleagues did not believe in. This personal attachment was described e.g. in the following words:

"It's become so personal. If someone is attached to [an idea], 'I've been thinking, I've been drawing this for a year. You want to kill my work?' Really. Go up and talk to these guys who have worked here for 15-20 years. And they have this fantastic idea that someone came up with, and developed this and spent so much time. And after two years, someone's going to come, 'no, we're killing it', and you're going to be responsible for killing it. You're going to realize that yourself. No, there's too much attachment, personal attachments for that. And there's not enough thinking about the business there. Do the figures stack up? You've been working on this for two years, and the product you're targeting, this customer segment."

\subsubsection{Slowness and rigidity}

Some of the interviewees also described slowness and rigidity $(n=17)$ as a hindrance for change and development. The industry in general was described to be slow when it came to making decisions and testing or implementing new ideas. Supporting functions inside the company were described as often insufficient or too rigid. This was something that further delayed some advancement efforts or 
projects. Also having to use one's own time on supporting functions as well as the slow pace of things going ahead came up as challenges.

Other hindrances to development and change could be found in the processes, use of resources and the working culture.

\section{DIscussion}

Seeking to illuminate the challenges in adopting new ways of working to transform development practices, the current study investigated the perceptions of culture and practices in a large industrial technology-based company and the perceived needs and challenges product development professionals saw in transitioning towards more design thinking oriented ways of working. Being based on a small number of interviews in a single organization, the results of the current study cannot be generalized into other contexts, but they do represent a first step in clarifying the types of challenges and needs that product developers experience in such transitions.

First, the results suggest that integrating collaborative and experimentative design practices into an organization requires a shared understanding. Having existing relationships for collaboration with customers helps in establishing new co-creational practices between stakeholders. In line with Elsbach and Stigliani (2018), a siloed organization was seen as a hindrance to expanding development activities from inventions to innovations. Indeed, the lack of a culture and practices for collaboration was seen as the single most large hindrance in this case study. In addition to limiting information sharing, this also resulted in a lack of questioning, and a focus on well-defined problems instead of striving for innovation. The interviewees unanimously voiced a lack of collaboration. While cocreation is often suggested as one way to overcome challenges in collaboration, the interviewees struggled to implement more co-creative ways because of the siloed organization and the lack of established practices for collaboration. Whenever co-creation and sprint pilots had been engaged in, the experience and feedback had been positive. However, despite managerial level interest in utilizing co-creation, companies often lack structured processes to recognize opportunities for co-creation and not all possibilities or forms of co-creation are considered (Frow et al., 2015). Indeed, the lack of established practices for collaboration was one of the perceived causes for lacking customer-oriented approaches in the current study as well.

While the interviewees shared an understanding of needing to transform collaboration practices, the deep-rooted notions of innovations deriving rather exclusively from technology inventions was not challenged or even recognized by all interviewees. This seemed to be more contested ground within the organization, and in the implicit rather than explicit vocabulary of the company. The technology focus combined with the silos in collaboration led to incremental development, but tackling this remained difficult without a shared recognition of it being rooted in the technology focus. As such, the results suggest further nuances to the bidirectional influence of organizational culture and methods reported by Elsbach and Stigliani (2018). Even though the siloed culture made co-creation difficult, this seemed to be a challenge recognized widely enough. The interviewees reported gaining support relatively easily for piloting practices to combat these challenges - thus, in the most "hostile" culture against collaboration, efforts to introduce collaboration-inducing methods seemed to be most fruitful. On the other hand, focusing on incremental technological development and inventions - a lesser issue that was not brought up by all interviewees - seemed to simultaneously be a less established, less agreed-upon issue. Also, efforts to introduce new needfinding without a focus on collaboration practices were not as quick to gain support. Perhaps counterintuitively then, the least "fertile" cultural ground can actually offer a more effective starting point for introducing new methods than a somewhat challenging premise.

Successful product innovations can have the power to ignite organizational change on strategic level and renewal of design principles to follow, and vice versa (Ravasi \& Lojacono, 2005). The results of the current study illustrate this bidirectional relationship, as strategic decisions such as unallocated experimentation budget enabled experimenting, while good results from previous experimental approaches generated a managerial level will for utilizing these approaches more widely. Indeed, the company culture and culture of collaboration also in this case study was in a need of restructuring, and there was a strategic level need for transforming development efforts in order to create innovation beyond only individual or grass-root efforts. Unless change is supported by transformational leadership (Gumusluoglu \& Ilsev, 2009; Jung et al., 2003) and new ways of working are integrated 
deeply into the company culture and ways of working, they are in danger of perishing if at some point pressure to push change is no longer present (Kotter, 1995). Design thinking should be approached as an organizational paradigm shift instead of only process and methods (Collins, 2013). If an organization is striving to incorporate design thinking processes, co-creation, and methods that are included in those processes, organizational and especially managerial level support should be provided to the individual champions pushing the new ways of working.

While further work is needed to explore product developers' experiences in introducing new ways of working in different organizational contexts (such as different types of companies and different industries), the current results from an industrial technology company suggest that practitioners hoping to push change in their organization might be best off starting from where ever consensus on problematic issues prevails, even if the challenge is seemingly extensive. Starting the change from a smaller, but opinion dividing challenge might turn out to be much harder than tackling a bigger, mutually recognized issue bit by bit. Also, being mindful of the co-evolvement of practices and culture when analysing current challenges in an organization is a good start in transforming practice. Even though the focus would be on introducing new methods or improving existing procedures, one should look for potential root causes and co-dependencies in the wider culture and practices of the organization in order to develop ways of working in a sustainable way. On the other hand, this bidirectional influence of organizational culture and methods can work in the change agents benefit when tackling challenges widely acknowledged in the organization, providing surprising points of leverages in the face of large transformations.

\section{REFERENCES}

Adams, R.S, Turns, J. and Atman, C.J. (2003), "Educating effective engineering designers: the role of reflective practice”, Design Studies, Vol. 24 No. 3, pp. 275-294. https://doi.org/10.1016/S0142-694X(02)00056-X

Amabile, T.M., Conti, R., Coon, H., Lazenby, J. and Herron, M. (1996), “Assessing the work environment for creativity”, Academy of Management Journal, Vol. 39 No. 5, p. 1154. https://doi.org/10.5465/256995

Amabile, T.M., Schatzel, E.A., Moneta, G.B. and Kramer, S.J. (2004), "Leader behaviors and the work environment for creativity: perceived leader support”, The Leadership Quarterly, Vol. 15 No. 1, pp. 5-32. https://doi.org/10.1016/j.leaqua.2003.12.003

Anderson, N., Potočnik, K. and Zhou, J. (2014), "Innovation and Creativity in Organizations: A State-of-theScience Review, Prospective Commentary, and Guiding Framework”, Journal of Management, Vol. 40 No. 5, pp. 1297-1333. https://doi.org/10.1177/0149206314527128

Body, J. (2008), "Design in the Australian taxation office.” Design Issues, Vol. 24 No. 1, pp. 55-67. https://doi.org/10.1162/desi.2008.24.1.55

Braun, V. and Clarke, V. (2006), "Using thematic analysis in psychology." Qualitative Research in Psychology, Vol. 3 No. 2, pp. 77-101. https://doi.org/10.1191/1478088706qp063oa

Brown, T. (2009), Change by design. Harper Collins, New York.

Buchanan, R. (1992), "Wicked problems in design thinking”, Design Issues, Vol. 8 No. 2, pp. 5-21. https://doi.org/10.5040/9781474282932.0019

Carlgren, L., Elmquist, M. and Rauth, I. (2014), "Design thinking: Exploring values and effects from an innovation capability perspective", The Design Journal, Vol. 17 No. 3, pp. 403-423. https://doi.org/10.2752/175630614X13982745783000

Carlgren, L., Rauth, I. and Elmquist, M. (2016), "Framing design thinking: The concept in idea and enactment", Creativity and Innovation Management, Vol. 25 No. 1, pp. 38-57. https://doi.org/10.1111/caim.12153

Carr, S.D., Halliday, A., King, A.C., Liedtka, J., Lockwood, T. (2010), “The influence of design thinking in business: Some preliminary observations”, Design Management Review, Vol. 21 No. 3, pp. 58-63. https://doi.org/10.1111/j.1948-7169.2010.00080.x

Coakley, L.A., Roberto, M.A. and Segovis, J.C. (2014), "Meeting the Challenge of Developing Innovative Problem-Solving Students Using Design Thinking and Organizational Behavior Concepts", Business Education Innovation Journal, Vol. 6 No. 2, pp. 34-43.

Collins, H. (2013), “Can design thinking still add value?”, Design Management Review, Vol. 24 No. 2 , pp. 35-39. https://doi.org/10.1111/drev.10239

Drews, C. (2009), "Unleashing the full potential of design thinking as a business method", Design Management Review, Vol. 20 No. 3, pp. 39-44. https://doi.org/10.1111/j.1948-7169.2009.00020.x

Elsbach, K.D. and Stigliani, I. (2018), "Design thinking and organizational culture: A review and framework for future research", Journal of Management, Vol. 44 No. 6, pp. 2274-2306. https://doi.org/10.1177/0149206317744252 
Frow, P., Nenonen, S., Payne, A. and Storbacka, K. (2015), "Managing co-creation design: A strategic approach to innovation", British Journal of Management, Vol. 26 No. 3, pp. 463-483. https://doi.org/10.1111/14678551.12087

Gumusluoglu, L. and Ilsev, A. (2009), “Transformational leadership, creativity, and organizational innovation”, Journal of business research, Vol. 62 No. 4, pp. 461-473. https://doi.org/10.1016/j.jbusres.2007.07.032

Jung, D.I., Chow, C. and Wu, A. (2003), "The role of transformational leadership in enhancing organizational innovation: Hypotheses and some preliminary findings", The leadership quarterly, Vol. 14 No. 4-5, pp. 525-544. https://doi.org/10.1016/s1048-9843(03)00050-х

Kim, J. and Wilemon, D. (2002), “Strategic issues in managing innovation's fuzzy front-end”, European Journal of Innovation Management, Vol. 5 No. 1, pp. 27-30. https://doi.org/10.1108/14601060210415153

Kotter, J.P. (1995), "Leading change: Why transformation efforts fail”, Harvard Business Review, May-June.

Lewis, M.W., Welsh, M.A., Dehler, G.E. and Green, S.G. (2002), "Product development tensions: exploring contrasting styles of project management", Academy of Management Journal, Vol. 45 No. 3, pp. 546-564. https://doi.org/10.2307/3069380

Liu, Z. and Schonwetter, D. J. (2004), “Teaching creativity in engineering”, International Journal of Engineering Education, Vol. 20 No. 5, pp. 801-808.

Martin, R. L. (2009), The design of business: Why design thinking is the next competitive advantage. Harvard Business School Press, Cambridge, MA.

McDonough, E.F. III and Barczak, G.B. (1991), "Speeding up new product development: the effects of leadership style and source of technology", Journal of Product Innovation Management, Vol. 8 No. 3 , pp. 203-211. https://doi.org/10.1111/1540-5885.830203

Micheli, P., Wilner, S.J., Bhatti, S.H., Mura, M. and Beverland, M.B. (2019), "Doing Design Thinking: conceptual review, synthesis, and research agenda", Journal of Product Innovation Management, Vol. 36 No. 2, pp. 124-148. https://doi.org/10.1111/jpim.12466

Mutanen, U. M. (2008), "Developing organisational design capability in a Finland-based engineering corporation: the case of Metso", Design Studies, Vol. 29, No. 5, pp. 500-520. https://doi.org/10.1016/j.destud.2008.03.005

Perks, H., Cooper, R. and Jones, C. (2005), "Characterizing the role of design in new product development: An empirically derived taxonomy”, Journal of Product Innovation Management, Vol. 22 No. 2, pp. 111-127. https://doi.org/10.1111/j.0737-6782.2005.00109.x

Rauth, I., Carlgren, L. and Elmquist, M. (2015), "Making it happen: Legitimizing design thinking in large organizations,” Design Management Journal, Vol. 9, No. 1, pp. 47-60. https://doi.org/10.1111/dmj.12015

Ravasi, D. and Lojacono, G. (2005), "Managing Design and Designers for Strategic Renewal”, Long Range Planning, Vol. 38 No. 1, pp. 51-77. https://doi.org/10.1016/j.lrp.2004.11.010

Ravasi, D. and Stigliani, I. (2012), "Product design: A review and research agenda for management studies", International Journal of Management Reviews, Vol. 14 No. 4, pp. 464-488. https://doi.org/10.1111/j.14682370.2012.00330.x

Rekonen, S. and Hassi, L. (2018), "Impediments for experimentation in novice design teams", International Journal of Design Creativity and Innovation, Vol. 6 No. 3-4, pp. 235-255. https://doi.org/10.1080/21650349.2018.1448723.

Sawyer, R.K. (2006), “Educating for innovation”, Thinking Skills and Creativity, Vol. 1 No. 1, pp. 41-48.

Seidel, V.P. and Fixson, S.K. (2013), “Adopting Design Thinking in Novice Multidisciplinary Teams: The Application and Limits of Design Methods and Reflexive Practices", Journal of Product Innovation Management, Vol. 30, pp. 19-33. https://doi.org/10.1111/jpim.12061

Valle, S. and Avella, L. (2003), "Cross-functionality and leadership of the new product development teams", European Journal of Innovation Management, Vol. 6 No. 1, pp. 32-47. https://doi.org/10.1108/14601060310456319

Vetterli, C., Uebernickel, F., Brenner, W., Petrie, C. and Stermann, D. (2016), “How Deutsche Bank's IT division used design thinking to achieve customer proximity", MIS Quarterly Executive, Vol. 15, pp. 37-53.

\section{ACKNOWLEDGMENTS}

This research would not have been possible without Design+, a research project funded by the Finnish Work Environment Fund (grant 117110), Aalto University, and participating companies. We are thankful for the funding, support of the larger research team, as well the time of the interviewees. 